\title{
Alternatif Aspal Modifikasi Polimer dengan Menggunakan Sampah Plastik Kemasan Makanan
}

\author{
Alternative of Asphalt Polymer Modification by Using Food Plastic \\ Packaging Waste
}

\author{
Muhammad Hadid ${ }^{1, a)}$, Ana Ubudiyah ${ }^{1, b)}$ \& Dyah Wahyu Apriyani ${ }^{1, c)}$ \\ ${ }^{1)}$ Prodi Teknik Sipil, Jurusan Teknik Sipil dan Perencanaan, Institut Teknologi Kalimantan, \\ Balikpapan.
}

Koresponden : ${ }^{a}$ hadid@lecturer.itk.ac.id, ${ }^{b}$ anaubud27@gmail.com \&

${ }^{c)}$ dyahwahyuap@lecturer.itk.ac.id

\begin{abstract}
ABSTRAK
Kondisi jalan di kota balikpapan banyak mengalami kerusakan, selain itu, ketersediaan aspal belum bisa memenuhi kebutuhan aspal karena $45 \%$ jalan di kota Balikpapan masih menggunakan kerikil dan tanah (DPU kota Balikpapan, 2015). Selain itu, Balikpapan juga mengalami masalah di aspek lingkungan yaitu sampah. Gibran (2017) berpendapat bahwa $13.51 \%$ sampah yang ada di koata Balikpapan adalah plastik. Plastik merupakan salah satu sampah yang sulit untuk di daur ulang. Sehingga, untuk menyelesaikan dua permasalahan tersebut dilakukan penelitian aspal modifikasi polimer dengan memanfaatkan sampah plastik kemasan makanan. Proses pembuatan aspal modifikasi polimer dilakukan sesuai dengan standar spesifikasi bina marga devisi 6 revisi 3, dimana proses pencampuran polimer dilakukan pada saat campuran beraspal panas dilaksanakan pada suhu $145^{\circ} \mathrm{C}-155^{\circ} \mathrm{C}$. Dari hasil penelitian yang dilakukan didapatkan variasi kadar aspal yang digunakan pada campuran adalah 5\%, 5.5\%, 6\%, 6.5\%, dan 7\%. Dan didapatkan kadar aspal optimum adalah 5.3\%. Dari kadar aspal optimimum dilakukan pencampuran polimer dengan variasi $0 \%, 1 \%, 2 \%, 3 \%$ dan $4 \%$. Hasil pengujian menunjukkan kadar polimer optimim adalah $0.5 \%$ polimer dan maksimum $1 \%$. Aspal modifikasi polimer memiliki nilai stabilitas yang tinggi yaitu $23.64 \%$ lebih besar jika dibandingkan dengan aspal konvensional. Selain itu, nilai rongga pada campuran $5.74 \%$ lebih besar dibandingkan aspal konvensional.
\end{abstract}

Kata Kunci : manajemen infrastruktur, aspal, modifikasi polimer, stabilitas perkerasan

\section{PENDAHULUAN}

Aspal merupakan bahan pengikat perkerasan lentur pada jalan, yang umumnya digunakan di Kota Balikpapan. DPU Kota Balikpapan (2015) dalam buku Balikpapan Dalam Angka 2015 menyampaikan bahwa, $55 \%$ akses jalan dikota Balikpapan terbuat dari Aspal dan 25\% diantaranya dalam kondisi rusak. Hal ini dapat disimpulkan bahwa ketersediaan aspal di Balikpapan masih kurang karena $45 \%$ jalan yang ada masih menggunakan kerikil dan tanah. Selain itu, Akses jalan di Balikpapan masih banyak mengalami kerusakan. Hal ini disebabkan karena beberapa faktor, mulai dari kondisi tanah dasar hingga perkerasan yang digunakan dalam membuat akses jalan. Selain itu, Balikpapan juga memiliki permasalahan dibidang lingkungan hidup yaitu sampah. Gibran (2017) berpendapat bahwa sampah yang ada di Balikpapan terdiri atas $59.4 \%$ organik, $13.51 \%$ plastik, $12.26 \%$ kertas, $10.62 \%$ aluminium, $1.97 \%$ kain, $0.81 \%$ kaleng, $0.09 \%$ logam, $1.19 \%$ kaca, dan $0.16 \%$ lain-lain. Dan sampah plastik merupakan sampah yang daur ulangnya membutuhkan waktu yang lama. 
Jalan sendiri merupakan salah satu aset infrastruktur transportasi yang mengalami perubahan akibat pembebanan lalu lintas, cuaca, lingkungan, dan perilaku pengguna jalan. Jalan harus dikelola sesuai dengan prinsip Manajemen Aset Infrastruktur. Pembangunan dan pemeliharaan jalan harus dilakukan secara ekonomis. Menggunakan campuran baru aspal, adalah salah satu cara untuk membuat pengelolaan perkerasan jalan menjadi ekonomis (Suprayitno \& Soemitro, 2018; Widayanti dkk, 2018). Pembangunan jalan hendaknya dilakukan dengan menggunakan aspal dan campuran material yang menghasilkan nilai stabilitas yang tinggi sehingga dapat mencegah terjadinya kerusakan pada jalan. Selain itu, dibutuhkan pula campuran Aspal yang menggunakan kadar Aspal yang rendah sehingga, dapat memenuhi ketersediaan aspal yang ada. Jalan yang menggunakan campuran aspal dengan nilai stabilitas yang tinggi dapat meningkatkan pelayanan dari segi kekuatan dan daya tarik antar agregat pada campuran aspal. Sehingga, jalan dapat memiliki ketahanan terhadap kerusakan. Seiring dengan banyaknya perbaikan dan pembangunan jalan di Balikpapan maka kebutuhan material Aspal juga akan terus meningkat. Akan tetapi, ketersediaan Aspal belum bisa memenuhi kebutuhan yang ada selain itu, Aspal yang digunakan harus berkualitas karena Seiring dengan berjalannya waktu aspal akan mengalami kerusakan baik akibat air, keretakan, pembangunan utilitas dan lainnya. Kerusakan jalan yang terjadi dapat mengurangi kenyaman dalam berkendara atau bahkan dapat menumbulkan kecelakaan. Kerusakan jalan yang terjadi biasanya dipengaruhi oleh stabilitas aspal. Maka perlu dilakukan manjemen asset infrastruktur jalan raya yang baik agar dapat memberikan pelayanan jalan yang baik.

Salah satu upaya yang dapat dilakukan untuk meningkatkan nilai stabilitas pada campuran Aspal sekaligus mengurangi kadar Aspal dalam campuran antara lain dengan menambahkan bahan aditif pada campuran Aspal. Salah satu bahan aditif yang dapat ditambahkan adalah polimer. Polimer atau biasa dikenal dengan plastik umumnya dapat kita lihat dalam kehidupan sehari-hari. Bahkan polimer juga menjadi bahan untuk membuat kemasan makanan dan produk-produk yang dijual dipasaran yang selanjutnya akan menjadi sampah apabila telah digunakan. Sehingga, Polimer yang digunakan sebagai bahan campuran aspal dapat berasal dari sampah plastik. Oleh karena itu, perlu dilakukan penelitian mengenai aspal modifikasi agar dapat menghasilkan komposisi aspal modifikasi polimer dengan stabilitas yang tinggi dan dengan kadar aspal yang rendah. Selain itu, penelitian ini juga bertujuan untuk mengoptimalkan penggunaan aspal dan memanfaatkan ketersediaan sampah plastik yang ada di Balikpapan.

Proses pembuatan campuran aspal dan polimer ini mengacu pada penelitian-penelitian sebelumnya yang dilakukan oleh beberapa pihak. Gibran (2017) melakukan penelitian di TPA Manggar Balikpapan dan dari hasil penelitian dapat diketahui bahwa produksi sampah terbanyak kedua di TPA Manggar Balikpapan setelah sampah organik adalah sampah plastik yaitu sebesar $13.51 \%$. Oleh karena itu, dilakukan penelitian dengan menggunakan polimer yaitu sampah plastik kemasan makanan untuk bahan campuran aspal sebagai alternatif bahan aditif untuk memingkatkan nilai stabilitas pada campuran aspal. Polimer yang digunakan sebagai alternatif zat aditif pada campuran aspal antara lain Polimer jenis Polyethylene Terephthalate (PET) yang biasanya digunakan pada kemasan makanan yang umumnya dijual di pertokoan, mini market dan pedagang lainnya. Penambahan sampah plastik kemasan makanan dilakukan dengan cara memotong sampah menjadi bagian bagian kecil dan mencampurkannya pada proses pencampuran setelah dilakukannya pencampuran aspal dan agregat dalam kondisi panas yang mencapai suhu $145-155^{\circ} \mathrm{C}$ sesuai dengan Spesifikasi Umum Perkerasan Aspal. Setelah itu akan dilakukan uji titik lembek, titik nyala, dan Marshall yang dapat menyajikan nilai stabilitas pada campuran Aspal dan polimer. Umam dkk (2007) membahas mengenai tempertur transisi yang dimiliki oleh polimer jenis PET adalah $170^{\circ} \mathrm{C}$. sehingga polimer dapat dicampurkan pada Aspal pada suhu dibawah suhu transisi. Hal ini berujuan agar polimernya terekstak dengan baik tanpa harus berubah wujud menjadi gas. Suhardi dkk (2016) melakukan peneletian dan dapat diketahui bahwa nilai variasi campuran 
polimer berupa PVC pada aspal antara lain 0\%, 2\%, 3\%, 4\%, 8\%, dan 12\% dengan kadar Aspal $5-7 \%$.

Penggunaan sampah kemasan makanan sebagai zat aditif pembuatan Aspal bertujuan untuk menghasilkan Aspal yang memiliki nilai stabilitas tinggi dan mengandung kadar Aspal yang rendah. Selain itu, penelitian ini juga bertujuan untuk menemukan alternatif pemanfaatan sampah plastik sehingga dapat mengurangi jumlah sampah yang ada di Balikpapan. Sedangkan Dari penelitian yang akan dilakukan, akan didapatkan hasil berupa komposisi aspal modifikasi polimer yang memiliki stabilitas yang tinggi dan mengandung kadar aspal yang rendah sehingga, dapat meningkatkan kualitas pembangunan dan perbaikan jalan, memenuhi ketersediaan aspal yang ada.serta meningkatkan kenyamanan dalam berkendara.

\section{STUDI PUSTAKA} berikut.

Adapun penelitian terdahulu yang mendukung penelitian ini dapat dilihat pada Tabel 1

Tabel 1. Penelitian Terdahulu

\begin{tabular}{llll}
\hline \multicolumn{1}{c}{ Nama Peneliti } & \multicolumn{1}{c}{ Judul Penelitian } & Tahun & \multicolumn{1}{c}{ Hasil Penelitian } \\
\hline Anita & Pengaruh Penggunaan & 2015 & polimer yang digunakan adalah polimer jenis \\
Rahmawa & Limbah Plastik & & $\begin{array}{l}\text { polipropilena (PP), dilakukan pencampuran yaitu } \\
\text { dengan kadar aspal 5\%, 6\%, dan 7\% dan kadar polimer }\end{array}$ \\
ti dan & Polipropilena sebagai & & PP 0\%, 2\%, 5\%, dan 10\%. Didapatkan kesimpulan \\
Rama & pengganti agregat pada & & bahwa penambahan polimer jenis PP menambah nilai \\
Rizana & campuran laston & & pada stabilitas dan kelelahan akan tetap, nilai void juga \\
& terhadap karakteristik & & semakin meningkat.
\end{tabular}

\begin{tabular}{|c|c|c|c|}
\hline Suhardi, Priyo & Studi Karakteristik & 2016 & Polimer yang digunakan adalah limbah botol plastik \\
\hline Pratomo, dan Hadi & Marshall Pada & & sebagai polimer. Kadar polimer yang digunakan adalah \\
\hline Ali & $\begin{array}{l}\text { Campuran Aspal } \\
\text { Dengan Penambahan } \\
\text { Limbah Botol Plastik }\end{array}$ & & $\begin{array}{l}1.5 \%, 2.5 \%, 3.5 \%, 4.5 \%, 5.5 \% \text { dan } 6.5 \% \text { dengan kadar } \\
\text { aspal } 6.38 \% \text { sampai dengan } 6.5 \% \text {. didapatkan hasil } \\
\text { bahwa nilai optimum stabilitas yang tinggi, terdapat } \\
\text { pada kadar polimer yaitu } 3 \% \text {. Akan tetapi } \\
\text { selainbertambahnya nilai stabilitas, kadar void juga } \\
\text { semakin meningkat. }\end{array}$ \\
\hline
\end{tabular}

\begin{tabular}{|c|c|c|c|}
\hline $\begin{array}{l}\text { JF. Soandrijanie } \\
\text { Linggo dan Juliyus } \\
\text { Yoga Kurniawan }\end{array}$ & $\begin{array}{l}\text { Penggunaan PVC } \\
\text { Sebagai Bahan Tambah } \\
\text { pada Beton Aspal }\end{array}$ & 2015 & $\begin{array}{l}\text { polimer yang digunakan adalah polimer jenis PVC. } \\
\text { Campuran aspal yang digunakan adalah } 5 \% \text { sampai } \\
\text { dengan } 7 \% \text { dan kadar polimer yang digunakan adalah } \\
0 \%, 2 \%, 3 \%, 4 \%, 8 \% \text {, dan } 12 \% \text {. Kadar optimum yang } \\
\text { dihasilkan adalah pada campuran dengan } 6 \% \text { aspal dan } \\
8 \% \text { PVC }\end{array}$ \\
\hline
\end{tabular}

\begin{tabular}{lll}
\hline Mashuridan Joi & Pemanfaatan Material 2011 & penelitian menggunakan tiga jenis bahan aditif yang \\
Fredy Batti & Limbah pada Campuran & berbeda antara lain PVC, Styrofoam, dan debu sisa \\
& Beton Aspal Campuran & PVil pembakaran batu bara. Dari hasil penelitian kadar \\
Panas & sampai dengan 6\%. Sedangkan kadar Styrofoam \\
& optimum yang dapat digunakan sekitar 6\% sampai \\
& dengan 10\%. Sedangkan pada sisa pembakaran batu \\
& bara kadar optimum yang dapat digunakan yaitu $4 \%$ \\
& sampai dengan $8 \%$.
\end{tabular}

Sehingga, variasi kadar polimer yang akan digunakan yaitu $0 \%, 1 \%, 2 \%, 3 \%$, dan $4 \%$ sesuai dengan penelitian terdahulu. 


\section{METODA PENELITIAN} berikut :

Sistematika penulisan makalah bisa disusun dalam beberapa alternative susunan sebagai

\section{Identifikasi Masalah}

Identifikasi Masalah dilakukan dengan melihat keadaan eksisting yang ada mulai dari kondisi jalan dan kondisi ideal yang seharusnya. Dan didapatkan ketidaksesuaian sehingga perlu ditemukan sebuah pemecahan agar dapat memberikan solusi terhadap keadaan eksisting agar dapat mencapai kondisi ideal. Setelah melihat keadaan eksisting jalan yang ada di Balikpapan menurut DPU kota Balikpapan dalam buku balikpapan dalam angka tahun 2015, didapatkan bahwa 45\% jalan di Balikpapan belum menggunakan Aspal atau masih menggunakan kerikil dan tanah Asli. Sedangkan dari total jalan yang sudah menggunnakan Aspal 25\% diantaranya dalam kondisi rusak. Sehingga, dapat disimpulkan bahwa perlu ada pemecahan masalah terkait jalan yang ada di Balikpapan. Selain itu, menurut Gibran tahun 2017 menyatakan bahwa banyaknya sampah plastik yang ada di Balikpapan yaitu sebesar $13.51 \%$ terbanyak kedua setelah sampah organik. Sampah plastik merupakan salah satu jenis sampah yang sulit untuk didaur ulang. Dari dua permasalahan ini menyebabkan perlunya dilakukan penelitian mengenai aspal modifikasi dengan menggunakan sampah plastik. Selain itu, sampah yang akan digunakan adalah sampah palstik kemasan makanan.

\section{Studi Literatur}

Studi literatur dilakukan dengan mengumpulkan data yang mendukung untuk dilakukannya penelitian lebih lanjut. Serta mengumpulkan refrensi pemecahan masalah yang serupa. Setelah itu, mencari penelitian sebelumnya dan mengkaitkan dengan sumber daya yang ada. mencari standar atau peraturan terkait solusi pemecahan masalah. sehingga, dapat ditemukan solusi yang akurat dalam pemecahan masalah. Selain itu, didapatkan cara penyelesaiannya yang disesuaikan dengan kondisi Balikpapan.

\section{Pengujian}

Pengujian dilakukan pada agregat dan material bitumen untuk mendapatkan karakteristik dari material penyusun campuran. Pengujian yang dilakukan dalam penelitian ini antara lain :

1. Agregat

Pengujian ukuran butir dan gradasi agregat berdasarkan SNI ASTM C136:2012 metode pengujian tentang analisis saringan agregat halus dan kasar. Pengujian daya serap agregat bedasarkan SNI 1969:2008 dan SNI 1970:2008 mengenai metode pengujian berat jenis dan penyerapan air pada agregat halus dan kasar. Pengujian keausan agregat berdasarkan SNI 2417:2008 mengenai metode pengujian keausan agregat dengan mesin los angeles.

2. Aspal

Pengujian berat jenis berdasarkan SNI 2441-2011 mengenai cara uji berat jenis aspal keras. Pengujian penetrasi berdasarkan SNI 2456-2011 mengenai penetrasi aspal. Pengujian titik lembek berdasarkan SNI 2434-2011 tentang pengujian titik lembek aspal. Pengujian daktilitas berdasarkan SNI 2432-2011 tentang pengujian daktilitas aspal.

3. Polimer

Polimer yang digunakan adalah polimer jenis PET yang pada umumnya digunakan dalam permbuatan berbagai macam produk konsumtif. Pada polimer akan dilakukan persiapan berupa pembersihan dan pencacahan sampah kemasan plastik yang akan digunakan. Kadar polimer yang akan digunaka disesuaikan dengan penelitian yang dilakukan suhardi dkk pada tahun 2016 yaitu 0\%, 1\%, 2\%, 3\% dan 4\%. 
4. Mix Design

Setelah melakukan pengujian terhadap Agregat dan Aspal maka perlu dilakukan perhitungan mix design untuk menentukan komposisi campuran yang akan digunakan dalam membuat campuran.

5. Pembuatan Briket

Proses pembuatan briket dilakukan dengan memasukkan hasil campuran aspal modifikasi pada cetakan yang berbentuk silinder dengan ukuran 4 inc untuk sampel aspal AC-WC. Selanjutnya, Proses pencetakan dilakukan dengan alat penumbuk dengan jumlah tumbukan tiap sampel adalah 150 tumbukan.

6. Uji Berat Isi

Pengujian berat isi dilakukan dengan membandingkan berat benda uji pada kondisi kering udara, kondisi kering permukaan, dan kondisi rendam dalam air Pengujian dilakukan dengan menimbang benda uji dalam kondisi dingin dan kering, selanjutnya merendam benda uji pada air dengan suhu ruang selama 24 jam.

7. Uji Marshall

Proses uji Marshall dilakukan dengan memasukkan benda uji pada alat mashall dan akan didapatkan nilai stabilitas, dan pelelehan.

8. Analisis Data dan Pembahasan

Analisis dilakukan terhadap hasil pengujian agregat, aspal, dan benda uji yang telah dibuat. Selain itu, dilakukan pembahasan hasil pengujian yang ada, hingga didapatkan hasil campuran Aspal modifikasi polimer yang menghasilkan nilai stabilitas yang tinggi dengan menggunakan kadar aspal yang optimal.

9. Kesimpulan dan Saran

Dari hasil analisa dan pembahasan yang telah dilakukan maka akan ditarik kesimpulan berupa komposisi Aspal modifikasi polimer yang optimal dan saran untuk penelitian selanjutnya.

\section{HASIL DAN PEMBAHASAN}

\section{Analisis Data}

Kadar polimer optimum didapatkan dari pengujian Marshall. Untuk itu diperlukan kondisi inisial sebelum penambahan polimer pada campuran panas. Kondisi inisial merupakan kondisi tanpa pencampuran polimer, bertujuan untuk mendapatkan kadar aspal optimum yang akan digunakan dalam pembuatan sampel campuran aspal dengan tambahan polimer. Pengujian yang dilakukan untuk mendapatkan kondisi inisial antara lain kombinasi agregat, penentuan kadar aspal perkiraan, pengujian Marshall. Setelah didapatkan kadar aspal optimum dari pengjian Marshall selanjutnya dilakukan pembuatan contoh dengan penambahan polimer dengan variasi persentase polimer $1 \%, 2 \%, 3 \%$, dan $4 \%$ berdasarkan studi literatur yang dilakukan.

1) Kombinasi Agregat

Dari hasil analisis saringan yang telah dilakukan maka data yang dioleh berupa persentase agregat yang lolos akan diperhitungkan untuk menentukan kadar agregat tiap sampelnya dengan menentukan persentase tiap jenis agregat. Dimana kombinasi agregat yang dihasilkan harus sesuai dengan standar dan ditampilkan dalam grafik batasan agregat untuk aspal AC-WC.

Hasil kombinasi agregat yang digunakan pada penelitian dapat dilihat pada Tabel 2 sebagai berikut. 
Tabel 2. Kombinasi Agregat

\begin{tabular}{ccccccccccccc}
\hline \multirow{2}{*}{ Jenis } & $\%$ & \multicolumn{10}{c}{ \% lolos saringan } \\
\cline { 2 - 12 } & $\mathbf{1 "}$ & $\mathbf{3 / 4 "}$ & $\mathbf{1 / 2 "}$ & $\mathbf{3 / 8}$ & $\mathbf{\# 4}$ & $\mathbf{\# 8}$ & $\mathbf{\# 1 6}$ & $\mathbf{\# 3 0}$ & $\mathbf{\# 5 0}$ & $\mathbf{\# 1 0 0}$ & $\mathbf{\# 2 0 0}$ \\
\hline CA & 9 & 100 & 100 & 54.6 & 24.1 & 2.11 & 1.88 & 1.78 & 1.76 & 1.73 & 1.53 & 1.43 \\
& 9 & 9 & 4.91 & 2.17 & 0.19 & 0.17 & 0.16 & 0.16 & 0.16 & 0.14 & 0.13 \\
\hline \multirow{2}{*}{ MA } & 54 & 100 & 100 & 93.9 & 85.7 & 51.1 & 21.1 & 14.6 & 10.9 & 9.43 & 7.66 & 6.71 \\
& & 54 & 54 & 50.7 & 46.3 & 27.6 & 11.4 & 7.86 & 5.91 & 5.09 & 4.14 & 3.62 \\
\hline \multirow{2}{*}{ FA } & 25 & 100 & 100 & 90.2 & 89.8 & 87.1 & 75.4 & 50.1 & 35.1 & 25.6 & 18.6 & 17.9 \\
& 25 & 25 & 22.5 & 22.5 & 21.8 & 18.9 & 12.5 & 8.77 & 6.41 & 4.66 & 4.49 \\
\hline \multirow{2}{*}{ SAND } & 10 & 100 & 100 & 92.4 & 87.6 & 74.5 & 61.8 & 47.9 & 34.9 & 16.9 & 3.94 & 2.46 \\
& 10 & 10 & 9.24 & 8.76 & 7.45 & 6.18 & 4.79 & 3.49 & 1.69 & 0.39 & 0.25 \\
\hline FILLER & 2 & 100 & 100 & 100 & 100 & 100 & 100 & 100 & 99.7 & 99.2 & 98.5 & 93.44 \\
& 2 & 2 & 2 & 2 & 2 & 2 & 2 & 1.99 & 1.98 & 1.97 & 1.87 \\
\hline TOTAL & 1 & 100 & 100 & 89.4 & 81.7 & 59 & 38.6 & 27.3 & 20.3 & 15.3 & 11.3 & 10.36 \\
\hline
\end{tabular}

Pada Tabel 2 dapat diketahui bahwa CA (Coarse Aggregate), MA (Medium Aggregate), FA (Fine Aggregate), sand atau pasir, dan filler merupakan agregat halus yang lolos ayakan \#200. Dari Tabel 2 dapat ditampilkan grafik gradasi agregat pada campuran dapat dilihat pada Gambar 1 sebagai berikut.

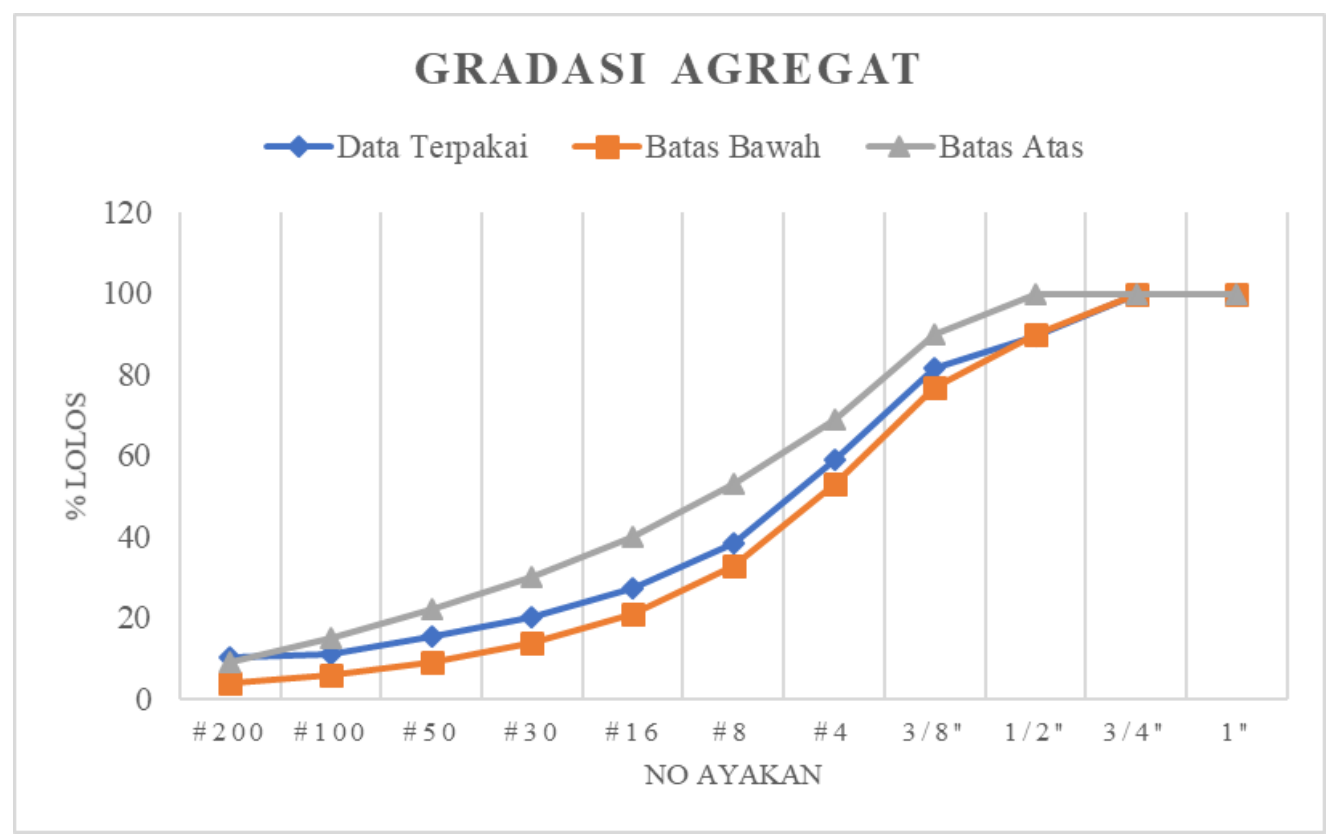

Gambar 1. Grafik Kombinasi Agregat

2) Komposisi Campuran

Dari hasil pengujian yang dilakukan terhadap analisa saringan dapat diketahui kadar aspal optimum teoritis $(\mathrm{Pb})$ sebagai berikut.

$$
\begin{aligned}
& \mathrm{Pb}=(0.035 \times \% \mathrm{CA})+(0.045 \times \% \mathrm{FA})+(0.18 \times 10.36) \\
& \mathrm{Pb}=(0.035 \times(100-81.67))+(0.045 \times(81.67-10.36)+(0.18 \times 10.36) \\
& \mathrm{Pb}=5.76 \% \approx 6 \%
\end{aligned}
$$

Sehingga, kadar aspal yang akan digunakan adalah 5\%, 5.5\%, 6\%, 6.5\%, dan 7\%.. 


\section{Pembahasan}

Dari penelitian yang telah dilakukan terhadap 5 variasi kadar aspal sesuai dengan perhitungan maka didapatkan hasil berupa stabilitas, VIM, VMA, VFA, dan Pelelehan. VIM (Void in Mix), VFA (Void Filled with Asphalt), dan VMA (Void in Mineral Agregat). Dari tiap benda uji yang dibuat. VMA merupakan nilai rongga yang terdapat antar agregat. VIM merupakan nilai rongga yang terdapat pada campuran aspal dan agregat. VFA merupakan nilai dari VMA yang terisi oleh aspal, sehingga VFA merupakan hubungan antara VMA dan VIM. Adapun hasil pengujian dapat dilihat pada Tabel 3 berikut.

Tabel 3. Hasil Perhitungan 5 Variasi Kadar Aspal

\begin{tabular}{|c|c|c|c|c|c|c|c|c|c|}
\hline $\begin{array}{c}\text { Kadar } \\
\text { Aspal }\end{array}$ & & Berat isi & $\begin{array}{c}\text { BD cam } \\
\text { max }\end{array}$ & VMA & VIM & VFA & Arloji & Stabilitas & Pelelehan \\
\hline$(\%)$ & & $\mathrm{gr} / \mathrm{cm}^{3}$ & & $(\%)$ & $(\%)$ & $(\%)$ & & $(\mathrm{kg})$ & $(\mathrm{cm})$ \\
\hline 5 & 1 & 2.23 & & & & & 73 & 1299.78 & 2.62 \\
\hline 5 & 2 & 2.31 & & & & & 67 & 1192.95 & 3.55 \\
\hline 5 & 3 & 2.33 & & & & & 63 & 1121.73 & 4.28 \\
\hline Rata-rata & & 2.29 & 2.43 & 15.2 & 5.49 & 63.8 & & 1204.82 & 3.48 \\
\hline 5.5 & 1 & 2.31 & & & & & 44 & 718.742 & 3.9 \\
\hline 5.5 & 2 & 2.30 & & & & & 75 & 1274.13 & 3.04 \\
\hline 5.5 & 3 & 2.31 & & & & & 106 & 1800.78 & 3.78 \\
\hline Rata-rata & & 2.31 & 2.41 & 15.0 & 4.20 & 72.1 & & 1264.55 & 3.57 \\
\hline 6 & 1 & 2.30 & & & & & 92 & 1397.63 & 3.39 \\
\hline 6 & 2 & 2.34 & & & & & 95 & 1613.90 & 5.15 \\
\hline 6 & 3 & 2.35 & & & & & 86 & 1531.25 & 2.91 \\
\hline Rata-rata & & 2.33 & 2.395 & 14.5 & 2.41 & 83.4 & & 1514.26 & 3.81 \\
\hline 6.5 & 1 & 2.34 & & & & & 98 & 1744.91 & 4.03 \\
\hline 6.5 & 2 & 2.33 & & & & & 79 & 1406.61 & 3.3 \\
\hline 6.5 & 3 & 2.32 & & & & & 78 & 1388.81 & 3.8 \\
\hline Rata-rata & & 2.33 & 2.37 & 14.9 & 1.38 & 90.8 & & 1513.44 & 3.71 \\
\hline 7 & 1 & 2.32 & & & & & 69 & 1172.20 & 5.29 \\
\hline 7 & 2 & 2.30 & & & & & 89 & 1511.97 & 3.05 \\
\hline 7 & 3 & 2.31 & & & & & 93 & 1579.93 & 3 \\
\hline Rata-rata & & 2.31 & 2.36 & 16.1 & 1.93 & 88.1 & & 1421.37 & 3.78 \\
\hline
\end{tabular}

Dengan menyesuaikan dengan standar Spesifikasi Bina Marga revisi 3 tahun 2010 devisi 6 dapat diketahui bahwa campuran yang sesuai dengaan standar antara lain dapat dilihat pada Gambar 2 berikut.

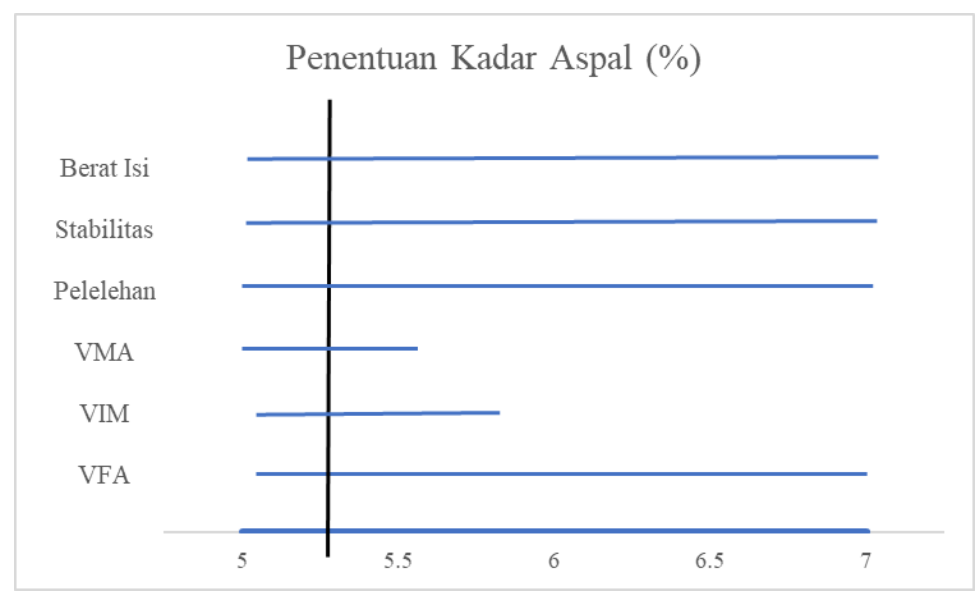

Gambar 2. Hasil Rekap Data 5 Variasi Kadar Aspal 
Sehingga, dapat diketahui kadar aspal optimum adalah 5.3\% sesuai dengan Gambar 2 Selanjutnya dilakukan pengujian dengan menggunakan kadar aspal optimum ditambahkan dengan variasi kadar polimer yaitu $0 \%, 1 \%, 2 \%, 3 \%$ dan 4\%. Adapun hasil pengujian dapat dilihat pada Tabel 4 berikut.

Tabel 4. Hasil Pengujian Dengan Variasi Polimer

\begin{tabular}{|c|c|c|c|c|c|c|c|c|c|}
\hline \multirow[b]{2}{*}{$\begin{array}{c}\text { Kadar } \\
\text { Polimer } \\
(\%)\end{array}$} & & \multirow[b]{2}{*}{$\begin{array}{l}\text { Berat isi } \\
\mathrm{gr} / \mathrm{cm} 3\end{array}$} & \multirow[b]{2}{*}{$\begin{array}{c}\text { BD } \\
\text { cam max }\end{array}$} & \multirow[b]{2}{*}{$\begin{array}{c}\text { VMA } \\
(\%)\end{array}$} & \multirow[b]{2}{*}{$\begin{array}{l}\text { VIM } \\
(\%)\end{array}$} & \multirow[b]{2}{*}{$\begin{array}{l}\text { VFA } \\
(\%)\end{array}$} & \multicolumn{3}{|c|}{ Stabilitas } \\
\hline & & & & & & & Arloji & $\begin{array}{l}\text { Terkoreksi } \\
\quad(\mathrm{kg})\end{array}$ & $\begin{array}{l}\text { Pelelehan } \\
\quad(\mathrm{cm})\end{array}$ \\
\hline 0 & 1 & 2.30 & & & & & 74 & 1124.18 & 3.2 \\
\hline 0 & 2 & 2.30 & & & & & 78 & 1184.95 & 3.6 \\
\hline 0 & 3 & 2.29 & & & & & 76 & 1154.56 & 3.4 \\
\hline 0 & 4 & 2.30 & & & & & 77 & 1308.11 & 3.7 \\
\hline 0 & 5 & 2.31 & & & & & 80 & 1424.42 & 4 \\
\hline Rata-rata & & 2.30 & 2.418 & 15.1 & 4.71 & 68.8 & & 1239.24 & 3.58 \\
\hline 1 & 1 & 2.33 & & & & & 110 & 1599.20 & 3.6 \\
\hline 1 & 2 & 2.28 & & & & & 105 & 1595.12 & 4 \\
\hline 1 & 3 & 2.29 & & & & & 102 & 1549.54 & 3.8 \\
\hline 1 & 4 & 2.29 & & & & & 94 & 1428.01 & 3.48 \\
\hline 1 & 5 & 2.28 & & & & & 98 & 1488.78 & 4.89 \\
\hline Rata-rata & & 2.29 & 2.418 & 15.3 & 4.98 & 67.5 & & 1532.13 & 3.95 \\
\hline 2 & 1 & 2.16 & & & & & 105 & 1595.12 & 4.7 \\
\hline 2 & 2 & 2.16 & & & & & 109 & 1655.88 & 4 \\
\hline 2 & 3 & 2.18 & & & & & 107 & 1625.50 & 3.9 \\
\hline 2 & 4 & 2.17 & & & & & 127 & 1929.33 & 4.3 \\
\hline 2 & 5 & 2.15 & & & & & 110 & 1671.08 & 5.1 \\
\hline Rata-rata & & 2.17 & 2.418 & 20.0 & 10.3 & 48.8 & & 1695.39 & 4.4 \\
\hline 3 & 1 & 2.12 & & & & & 109 & 1584.66 & 3.9 \\
\hline 3 & 2 & 2.15 & & & & & 122 & 1713.87 & 4.9 \\
\hline 3 & 3 & 2.16 & & & & & 119 & 1671.72 & 4.8 \\
\hline 3 & 4 & 2.15 & & & & & 126 & 1914.14 & 4.55 \\
\hline 3 & 5 & 2.14 & & & & & 120 & 1744.58 & 4.5 \\
\hline Rata-rata & & 2.14 & 2.418 & 20.8 & 11.2 & 46.4 & & 1725.79 & 4.53 \\
\hline 4 & 1 & 2.15 & & & & & 113 & 1642.81 & 3.57 \\
\hline 4 & 2 & 2.13 & & & & & 100 & 1453.82 & 3.62 \\
\hline 4 & 3 & 2.13 & & & & & 108 & 1570.13 & 4.4 \\
\hline 4 & 4 & 2.11 & & & & & 98 & 1424.74 & 4.8 \\
\hline 4 & 5 & 2.12 & & & & & 103 & 1497.43 & 3.3 \\
\hline Rata-rata & & 2.13 & 2.418 & 21.4 & 11.8 & 44.9 & & 1517.79 & 3.938 \\
\hline
\end{tabular}

Tabel 4 menunjukan bahwa semakin tinggi kadar polimer yang digunakan akan menambah Rongga dalam agregat (VMA) ini ditunjukan bahwa pada kondisi inisial atau kadar polimer $0 \%$ VMA bernilai $15.1 \%$. Penambahan polimer $1 \%$ dan $2 \%$ menghasilkan nilai VMA secara berturut-turut adalah $15.3 \%$ dan 20\%. Lebih jauh, berdasarkan Tabel 4 bahwa penambahan 3\% dan 4\% polimer didapatkan nilai VMA $20.8 \%$ dan $21.4 \%$. Dengan demikian dapat disimpulkan terkait VMA pada pengujian ini bertambah $43 \%$. Tren yang sama ditunjukan pada nilai Rongga Dalam Campuran (VIM). Penambahan aspal hingga 4\% meningkatkan nilai VIM dan stabilitas secara berurutan 138\%. Namun tren Rongga Terisi Aspal (VFA) berbeda dengan VMA dan VIM. Penambahan polimer hingga 4\% menurunkan nilai VFA sebesar 34.7\%. Hasil pengujian Marshall menunjukan stabilitas memiliki tren parabola. Penambahan polimer meningkatkan stabilitas namun pada titik tertentu penambahan polimer akan menurunkan stabilitas. Berdasarakan Tabel 4 maksimum stabilitas terjadi pada penambahan 
polimer 3\%. Tren pelelehan serupa dengan tren stabilitas, peningkatan kadar polimer meningkatkan nilai pelelehan hingga pada kadar polimer $3 \%$.

Sesuai dengan standar Spesifikasi Bina Marga Revisi 3 Tahun 2010 Devisi 6 untuk campuran beraspal panas modifikasi dapat diketahui kadar polimer yang sesuai standar dapat dilihat pada Gambar 3 berikut.

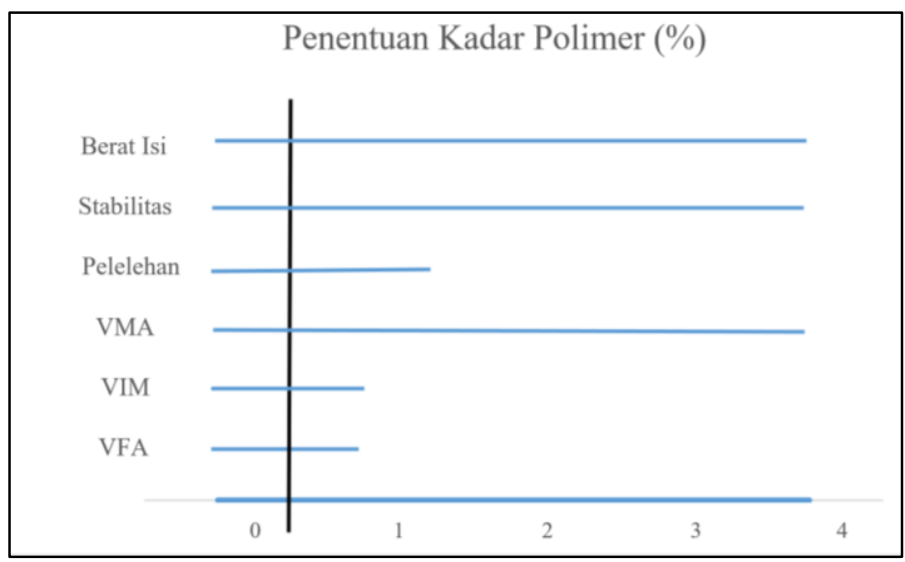

Gambar 3. Hasil Rekap Data Variasi Kadar Polimer

Dari Gambar 3 dapat diketahui kadar polimer optimum adalah $0.5 \%$. Adapun perbedaan antara aspal modifikasi polimer dengan aspal konvensional dapat dilihat pada Tabel 5 berikut.

Tabel 5. Perbandingan Aspal Konvensional dan Aspal Modifikasi Polimer

\begin{tabular}{cccc}
\hline Komponen & $\begin{array}{c}\text { Aspal konvensional } \\
\text { (Polimer (0\%)) }\end{array}$ & $\begin{array}{c}\text { Aspal modifikasi } \\
\text { (Polimer (0.5\%)) }\end{array}$ & $\begin{array}{c}\text { Perbandingan Aspal } \\
\text { konvensional dan } \\
\text { Aspal modifikasi } \\
\text { Polimer }\end{array}$ \\
\hline Berat isi campuran & $2.3 \mathrm{~kg} / \mathrm{cm}^{3}$ & $2.29 \mathrm{~kg} / \mathrm{cm}^{3}$ & $>0.45 \%$ \\
Stabilitas & $1239 \mathrm{~kg}$ & $1532 \mathrm{~kg}$ & $<23.65 \%$ \\
Pelelehan & $3.58 \mathrm{~cm}$ & $3.95 \mathrm{~cm}$ & $<10.33 \%$ \\
VIM & $4.7 \%$ & $4.97 \%$ & $<5.74 \%$ \\
VMA & $15.072 \%$ & $15.31 \%$ & $<1.58 \%$ \\
VFA & $68.77 \%$ & $65.96 \%$ & $>0.49 \%$ \\
\hline
\end{tabular}

Tabel 5 menunjukan bahwa aspal modifikasi untuk berat isi campuran lebih tinggi $0.45 \%$ namun untuk stabilitas dan pelelehan di bawah campuran aspal tanpa campuran polimer yakni lebih rendah $23.65 \%$ dan $10.33 \%$. untuk nilai VIM dan VMA campuran aspal dengan polimer lebih rendah $5.74 \%$ dan $1.58 \%$ dibandingkan dengan campuran tanpa polimer, tapi untuk nilai VFA penggunaan polimer lebih tinggi $0.49 \%$ dibandingkan dengan campuran tanpa polimer.

\section{KESIMPULAN}

Adapun kesimpulan yang didapatkan dari hasil penelitian aspal modifikasi polimer dengan menggunakan sampah plastik kemasan makanan adalah sebagai berikut.

1. Dari hasil pengujian didapatkan komposisi aspal modifikasi polimer yang terdiari atas kadar aspal optimum yaitu 5.3\%, dan kadar polimer optimum adalah $0.5 \%$

2. Dari hasil pengujian didapatkan perbandingan aspal modifikasi polimer dengan aspal konvensional yaitu, berat isi campuran $0.4 \%$ lebih kecil, Stabilitas $23.64 \%$ lebih besar, pelelehan $10.33 \%$ lebih besar, VIM $5.74 \%$ lebih besar, VMA $1.57 \%$ lebih besar, VFA 4.09\% lebih kecil. Sehingga, secara garis besar aspal modifikasi polimer lebih baik dibanding aspal konvensional. 


\section{DAFTAR PUSTAKA}

Bina Marga (2010). Spesifikasi Umum Bina Marga Tahun 2010 Revisi 3. Direktorat Jendral Bina Marga Kementrian Pekerjaan Uumum. Jakarta.

Gibran, Muhammad Hawwari. (2017). Kajian Pengelolaan Sampah di UPTD TPA Manggar Balikpapan. Laporan Kerja Praktek. Universitas Airlangga. Surabaya.

Joi, Mashuridan \& Batti, J.F. (2011), "Material limbah pada campuran benton aspal campuran panas" Majalah Ilmiah Mektek.

Rahmawati, Anita. \& Rizana, Rama. (2015). "Pengaruh penggunaan limbah plastik polipropilena sebagai pengganti agregat pada campuran laston terhadap karakteristik Marshall”. Konferensi Nasional Teknik sipil 7 (KoNTekS 7) UNS hal. 83.

SNI ASTM C136:2012. Metode Uji untuk Analisis Saringan Agregat Halus dan Agregat Kasar.

SNI 1969:2008. Cara Uji Berat Jenis Penyerapan Air Agregat Kasar.

SNI 1970:2008. Cara Uji Berat Jenis dan Peyerapan Air Agregat Halus.

SNI 2417:2008. Cara Uji Keausan Agregat dengan Mesin Abrasi Los Angeles.

SNI 2434-2011. Cara Uji Titik Lembek Aspal dengan Alat Cincin dan Bola (ring and ball).

SNI 2432-2011. Cara Uji Daktilitas.

SNI 2441-2011. Tentang Cara Uji Berat Jenis Aspal Keras.

SNI 2456-2011. Cara Uji Penetrasi Aspal.

Soandrijanie, Linggo, JF. \& Kurniawan, J.Y. (2015). "Penggunaan PVC sebagai bahan tambah pada beton aspal". Jurnal Teknik Sipil, Vol. 13, No. 3, Hal. 190-195.

Suhardi, Pratomo, P. \& Hadi Ali. (2016). "Studi Karakteristik Marshall pada campuran beraspal dengan penambahan limbah botol plastik". Jurnal Rekayasa Sipil dan Disain Edisi Juni 2016, Vol 4 No.2, Hal 248-293.

Suprayitno, H. \& Soemitro, R.A.A. (2018). "Preliminary Reflexion on Basic Principle of Infrastructure Asset Management". Jurnal Manajemen Aset Infrastruktur \& Fasilitas, Vol. 2, No. 1, Maret 2018, Hal. : 1-9.

Umam, K.A. \& Nur Himawan. Nurmawati. (2007). Struktur dan Sifat Polimer. Tugas S1. Universitas Indonesia. Jakarta.

Widayanti, A., Soemitro, R.A.A., Ekaputri, J.J. \& Suprayitno, H. (2018), "Kinerja Campuran Aspal Beton dengan Reclaimed Asphalt Pavement dari Jalan Nasional di Provinsi Jawa Timur”. Jurnal Manajemen Aset Infrastruktur \& Fasilitas, Vol 2 No.1, Hal 35-43. 